See discussions, stats, and author profiles for this publication at: https://www.researchgate.net/publication/285049749

\title{
Metabolic Pathways for Degradation of Aromatic Hydrocarbons by Bacteria
}

Article in Reviews of environmental contamination and toxicology · November 2015 DOI: 10.1007/978-3-319-23573-8_5

\section{CITATIONS}

18

5 authors, including:

\section{Guillermo Ladino-Orjuela}

Centro Universitário de Votuporanga

7 PUBLICATIONS 31 CITATIONS

$$
\text { SEE PROFILE }
$$

(8)

Roberto Da Silva

São Paulo State University

217 PUBLICATIONS 3,443 CITATIONS

SEE PROFILE
READS

2,127

Some of the authors of this publication are also working on these related projects:

ENFIRO View project

Project Application of enzymes in food science View project

Eleni Gomes

São Paulo State University 216 PUBLICATIONS 3,373 CITATIONS

$$
\text { SEE PROFILE }
$$

John Parsons

University of Amsterdam

165 PUBlications 2,874 CITATIONS

SEE PROFILE 


\title{
Metabolic Pathways for Degradation of Aromatic Hydrocarbons by Bacteria
}

\author{
Guillermo Ladino-Orjuela, Eleni Gomes, Roberto da Silva, \\ Christopher Salt, and John R. Parsons
}

\begin{abstract}
Contents

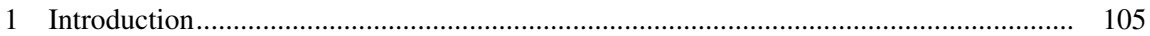

2 Biodegradation of Aromatic Compounds ..................................................................... 107

2.1 Aromatic Hydrocarbon Biodegradation Under Aerobic Conditions ...................... 108

2.2 Aromatic Hydrocarbon Biodegradation Under Anaerobic Conditions................... 112

3 Practical Applications of Knowledge About Metabolic Pathways ................................... 116

4 Summary ……................................................................................................... 116

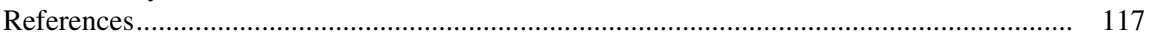

\section{Introduction}

The aromatic compounds present in the environment are from natural sources and anthropogenic activities. The chemical characteristic of these compounds is the presence of one benzene ring (monoaromatic hydrocarbon-MAHs) or more than one fused rings (polyaromatic hydrocarbon-PAHs) (Favre and Powell 2013). The ring provides structural and chemical stabilities due to a symmetric $\pi$-electron system and therefore recalcitrance of these compounds (Vogt et al. 2011). In accordance with Molecular Orbital Theory, in a molecule of benzene the $\mathrm{p}$ electrons on

\footnotetext{
G. Ladino-Orjuela $(\triangle) \bullet$ E. Gomes $\bullet$ R. da Silva

Laboratory of Biochemistry and Applied Microbiology, Institute of Biosciences,

Letters and Exact Sciences (IBILCE) - São Paulo State University (Unesp),

Rua Cristóvão Colombo, 2265, São José do Rio Preto, São Paulo 15013-000, Brazil

e-mail: ambos.ong@gmail.com; eleni@ibilce.unesp.br; dasilva@ibilce.unesp.br

C. Salt • J.R. Parsons

Institute for Biodiversity and Ecosystem Dynamics (IBED), Universiteit Van Amsterdam,

P.O. Box 94248, Amsterdam 1090 GE, The Netherlands

e-mail: christopher.salt@student.uva.nl; J.R.Parsons@uva.nl
} 
a

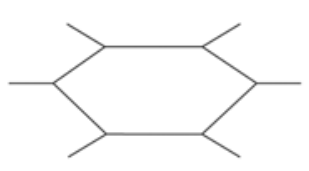

b

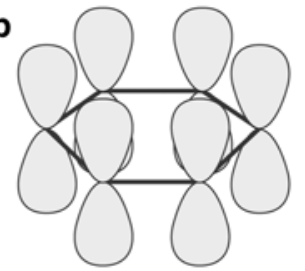

C

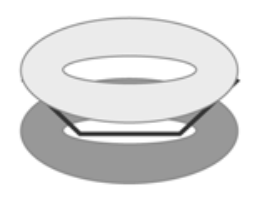

d

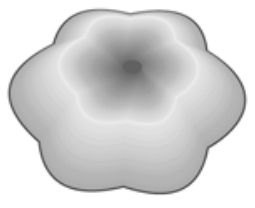

Fig. 1 Electron delocalization of $\pi$-electron system in benzene ring. (a) Shows the sigma-bonding framework of benzene. (b) Shows the $p$ orbitals which form the delocalized $\pi$-bonding system in benzene. (c) Shape of the $\pi$-electron clouds above and below the plane of the ring in benzene. (d) Electrostatic potential map of benzene (Bruice 2004)

each carbon atom are delocalized and contribute to the development of the so-called $\pi$ system. An electrostatic potential map of benzene (Fig. 1) shows that the electrons in the $\pi$-system are evenly distributed around the ring (Bruice 2004).

Aromatic hydrocarbons are classified as biological and non-biological compounds. Biological aromatic hydrocarbons are produced by plants and by microorganisms. In plants, this is mainly through the shikimic acid pathway (Ghosh et al. 2012) and microorganisms mainly via the malonic acid pathway (Zhan 2009). Capsaicin, estradiol, caffeine, theobromine, gallic acid, aromatic aminoacids (tyrosine, phenylalanine, and tryptophan), salicylic acid and the monolignols (p-coumaryl, coniferyl, and sinapyl) of lignin are the most well-known.

The monolignols are synthesized in plants via the shikimic acid pathway and are the most important natural aromatic compounds since they appear in large quantities in the environment as lignin and humic acids. p-coumaryl is a minor component of grass and forage type lignins, and coniferyl is the predominant lignin monomer found in softwoods (hence the name). Both coniferyl and sinapyl are the building blocks of hardwood lignin ( $\mathrm{Li}$ and Chapple 2010).

The main sources of non-biological aromatics hydrocarbons are the effluents from fuel, chemical, plastic, explosive, ink, metal, pharmaceutical, and electric industries among others (Table 1). These compounds are called xenobiotics in function of their non-biological origin and their bioaccumulation, toxicity and carcinogenic action are well documented (USEPA 2005).

The physic-chemical properties of aromatic hydrocarbons have environmental significance because they determine fate in soil, water and atmosphere. For instance, adsorption on soils or sediments, due to hydrophobicity, is a major factor in their transportation and eventual degradation (Karickhoff 1981). The soil organic carbonwater partitioning coefficient $\left(\mathrm{K}_{\mathrm{OC}}\right)$, that reflects the ratio between the quantity of the compound absorbed in the soil (normalized to organic carbon content) and the concentration in water has been used in predicting the mobility and bioavailability of organic soil contaminants. Low $\mathrm{K}_{\mathrm{OC}}$ values correlate to more mobile organic chemicals and higher bioavailability (Wilczyńska-Piliszek et al. 2012) (Table 1).

The United States Environmental Protection Agency (USEPA 2005) published in 1986 guidelines to characterize the human carcinogenic potential of agents according to the Weight of Evidence (WoE). The characterization was done by a six-category 
Table 1 Aromatic compounds from industrial activities

\begin{tabular}{l|l|l|l|l}
\hline Compound & Formula & WoE* & $\mathrm{K}_{\mathrm{oc}}$ & CASRN \\
\hline Aniline & $\mathrm{C}_{6} \mathrm{H}_{5} \mathrm{NH}_{2}$ & B2 & 0.96 & $62-53-3$ \\
\hline Phenol & $\mathrm{C}_{6} \mathrm{H}_{6} \mathrm{O}$ & D & 1.24 & $108-95-2$ \\
\hline Benzene & $\mathrm{C}_{6} \mathrm{H}_{6}$ & A & 1.82 & $71-43-2$ \\
\hline $2,4,6$ Trinitrotoluene & $\mathrm{C}_{6} \mathrm{H}_{2} \mathrm{CH}_{3}\left(\mathrm{NO}_{2}\right)_{3}$ & C & 2.48 & $118-96-7$ \\
\hline Bisphenol A & $\mathrm{C}_{15} \mathrm{H}_{16} \mathrm{O}_{2}$ & N.A. & 2.74 & $80-05-7$ \\
\hline Tetrachlorobenzene $1,2,3,4$ & $\mathrm{C}_{6} \mathrm{H}_{2} \mathrm{Cl}_{4}$ & N.A. & 4.60 & $634-66-2$ \\
\hline Benzo-a-pyrene & $\mathrm{C}_{20} \mathrm{H}_{12}$ & B2 & 5.98 & $50-32-8$ \\
\hline
\end{tabular}

${ }^{*}$ WoE weight of evidence approach, N.A. not applicable, $K_{o c}$ sorption coefficient $(\log \mathrm{L} / \mathrm{Kg})$, CASRN chemical abstract service registry numbers

alphanumeric classification system (A, B1, B2, C, D and E). Group A includes human carcinogenic agents and Group $\mathrm{E}$ is for substances with evidence of non-carcinogenicity. The approach outlined in USEPA's guidelines for carcinogen risk assessment (USEPA 2005) considers all scientific information in determining whether, and under what conditions, an agent may cause cancer in humans and provides a narrative approach to characterize carcinogenicity rather than categories (Table 1).

Among the techniques for the study of metabolic pathways of aromatic hydrocarbon degradation by bacteria, the molecular biology technique Stable Isotope Probing (SIP) is particularly interesting because it allows for detailed metabolic and taxonomic analysis. SIP involves the incorporation of heavy isotopes $\left({ }^{13} \mathrm{C},{ }^{15} \mathrm{~N}\right.$ or ${ }^{18} \mathrm{O}$ ) into newly synthesized nucleic acids allowing the metabolic capacity of cultivated or uncultivated microorganisms to be linked to taxonomic identity (Aanderud and Lennon 2011; Abu Laban et al. 2015; Cupples 2011; Rettedal and Brözel 2015; Taubert et al. 2012; Zhang et al. 2012b). Briefly, in the nucleic acid-based SIP with carbon, light ${ }^{12} \mathrm{C}$ nucleic acid and heavy ${ }^{13} \mathrm{C}$ nucleic acid (DNA or RNA) are separated through ultracentrifugation and then characterized by denaturing gradient gel electrophoresis (DGGE) or terminal restriction fragment length polymorphism (T-RFLP) and sequencing of 16S rRNA gene. These results are used for genomic and/or metagenomic analysis (Cupples 2011; Kim et al. 2014; Kleinsteuber et al. 2012; Zhang et al. 2012b). The protein-based SIP relies on the detection and quantification of the peptides that incorporate heavy isotope ${ }^{13} \mathrm{C}$ or ${ }^{15} \mathrm{~N}$ for proteomic and/or metaproteomic analysis using high-resolution mass spectrometry (Kleinsteuber et al. 2012; Taubert et al. 2012).

\section{Biodegradation of Aromatic Compounds}

The hydrophobicity and chemical stability of aromatic hydrocarbons, described above, give negligible biological activity to these molecules. Therefore, to break them down, in either aerobic or anaerobic conditions, bacteria need to destabilize the benzene ring through reversible and irreversible chemical modifications (Díaz et al. 2013). 
Table 2 TEAs (terminal electron acceptors) used by bacteria for aromatic hydrocarbon degradation

\begin{tabular}{|c|c|c|c|c|}
\hline \multicolumn{3}{|l|}{ Anaerobic } & \multirow{2}{*}{$\begin{array}{l}\text { Aerobic } \\
\text { Oxidized }\end{array}$} & \multirow{2}{*}{ 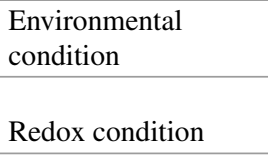 } \\
\hline $\begin{array}{l}\text { Highly } \\
\text { reduced }\end{array}$ & Reduced & $\begin{array}{l}\text { Moderately } \\
\text { reduced }\end{array}$ & & \\
\hline $\mathrm{CO}_{2}$ & $4^{2-} \mathrm{Fe}(\mathrm{III})$ & $\mathrm{Mn}(\mathrm{IV}) \quad \mathrm{NO}_{3}^{-}$ & $\mathrm{O}_{2}$ & $\begin{array}{l}\text { Terminal Electron } \\
\text { Acceptor (TEA) }\end{array}$ \\
\hline$\downarrow \mathrm{CH}_{4} \quad \mathrm{HS}$ & $\mathrm{Fe}(\mathrm{II})$ & $\mathrm{Mn}(\mathrm{II})$ & $\mathrm{H}_{2} \mathrm{O}$ & Products \\
\hline $\begin{array}{l}\text { Anaerobic } \\
-300 \quad-200\end{array}$ & $\begin{array}{l}\text { Facultative } \\
-100 \quad 0 \quad+100\end{array}$ & $0+200+300$ & $\begin{array}{l}\text { Aerobic } \\
+400+500+600+700\end{array}$ & $\begin{array}{l}\text { Microbial metabolism } \\
\mathrm{E}^{\circ}(\mathrm{mV})\end{array}$ \\
\hline
\end{tabular}

Downward arrow indicates products of TEAs reduction. Dashed arrow indicates sequential order of TEAs preferences from higher redox potential $\left(\mathrm{E}^{\circ}=+\right)$ to lower redox potential $\left(\mathrm{E}^{\circ}=-\right)$ (DeLaune and Reddy 2005; Gibson and Harwood C 2002)

In both aerobic and anaerobic pathways of aromatic hydrocarbon biodegradation a Terminal Electron Acceptor (TEA) is required. TEA determines the energy balance and the metabolic reaction used by microorganisms (Table 2) (Philipp and Schink 2012; Schink et al. 2000). However, studies with microcosms and stable isotope probing (SIP) have shown that, in environments dominated by a particular TEA, the dominant bacterial strain was not specialized to degrade the aromatic hydrocarbon being evaluated (Kleinsteuber et al. 2012; Pilloni et al. 2011). These results suggest that aromatic-degrading strains are specialized and the dominant bacterial strains are generalists and are able to use compounds other than aromatic hydrocarbons as carbon and energy sources (Staats et al. 2011).

The aerobic and anaerobic processes of aromatic hydrocarbon biodegradation have been divided (see also below) into upper pathways, which go from the original aromatic compound to so-called central intermediates, and lower pathways, which go from the ring cleavage of intermediates down to molecules for biomass (Cafaro et al. 2004; Carmona et al. 2009).

\subsection{Aromatic Hydrocarbon Biodegradation Under Aerobic Conditions}

In nature, oxygen is the most common and strongest oxidizing agent found (DeLaune and Reddy 2005). In this sense, bacteria will firstly use oxygen as the TEA to degrade aromatic hydrocarbons.

In aerobic conditions, the first step of upper pathways is an oxidation catalyzed by monooxygenases (hydroxylases) or by dioxygenases (Huijbers et al. 2014; Parales and Resnick 2004).

The monooxygenases catalyze the cleavage of the oxygen-oxygen bond of $\mathrm{O}_{2}$, inserting one oxygen atom into the aromatic ring while the other is reduced to $\mathrm{H}_{2} \mathrm{O}$ (Fig. 2). These enzymes are classified in eight groups according to their structure, sequence, type of reaction catalyzed and type of electron donor. The group A-B 


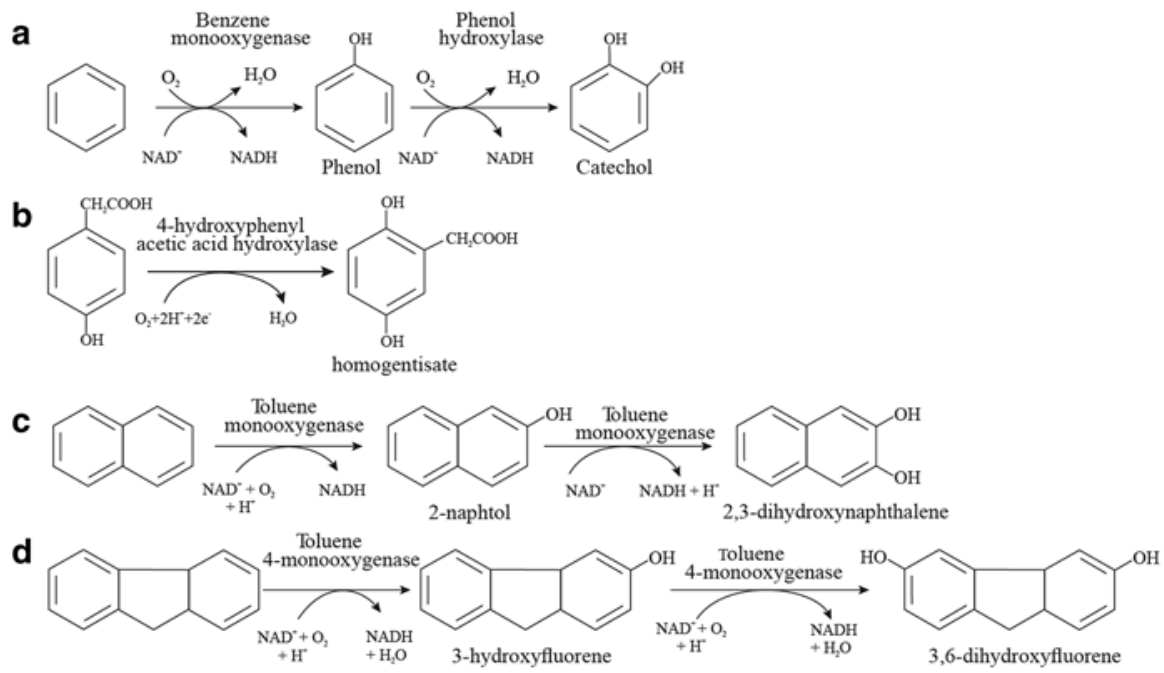

Fig. 2 Process of oxidation of benzene (a), 4-hydroxyphenyl acetic acid (b), naphthalene (c), and fluorene (d) catalyzed by monooxygenases

monooxygenases (EC 1.14.13) includes enzymes whose cofactor is the Flavin Adenine Dinucleotide (FAD) and the electron donor is the Nicotinamide Adenine Dinucleotide Phosphate NAD(P)H. They are able to catalyze hydroxylation, sulfoxidation, heteroatom oxygenation, $\mathrm{N}$-hydroxylation and oxidative decarboxylation reactions. Group C-D monooxygenases (EC 1.14.14) require FAD or flavin mononucleotide (FMN) as cofactor and $\mathrm{FMNH}_{2}$ or $\mathrm{FADH}_{2}$ as electron donor and catalyzes hydroxylation, sulfoxidation, oxidation, epoxidation and desulfurization reactions. Group E-G has FAD as cofactor and $\mathrm{FADH}_{2}$ or a substrate as electron donor. This group includes internal flavoprotein monooxygenases that reduce the flavin cofactor through substrate oxidation, and catalyze halogenation, sulfoxidation and oxidative decarboxylation (Huijbers et al. 2014).

Monooxygenases can oxidize both monoaromatic and polyaromatic hydrocarbons. Some examples are phenol hydroxylase and toluene/o-Xylene monooxygenase catalyzing benzene and phenol oxidation as reported by Cafaro et al. (2004) from Pseudomonas stutzeri OX1 and 4-hydroxyphenyl acetate 1-monooxygenase catalyzing oxidation of 4-hydroxyphenyl acetate as reported by Hareland et al. (1975) from P. acidovorans. In the case of PAHs, there was reported oxidation of naphthalene and fluorene catalyzed by a toluene 4-monooxygenase following a similar route to monoaromatic hydrocarbons (Tao et al. 2005) (Fig. 2).

While monooxygenases sequentially add hydroxyl groups to the aromatic ring, using molecular oxygen as substrate, forming phenols and then catechols, the dioxygenases catalyze, in the upper pathway, the reductive dihydroxylation of the aromatic ring forming cis-dihydrodiols (Fig. 3), then funneled by specific cis-dihydrodiol dehydrogenases to catechols as central intermediates. These dioxygenases are cofactor-requiring multicomponent heteromultimeric proteins (EC 1.14.12) (Parales and Resnick 2004). 

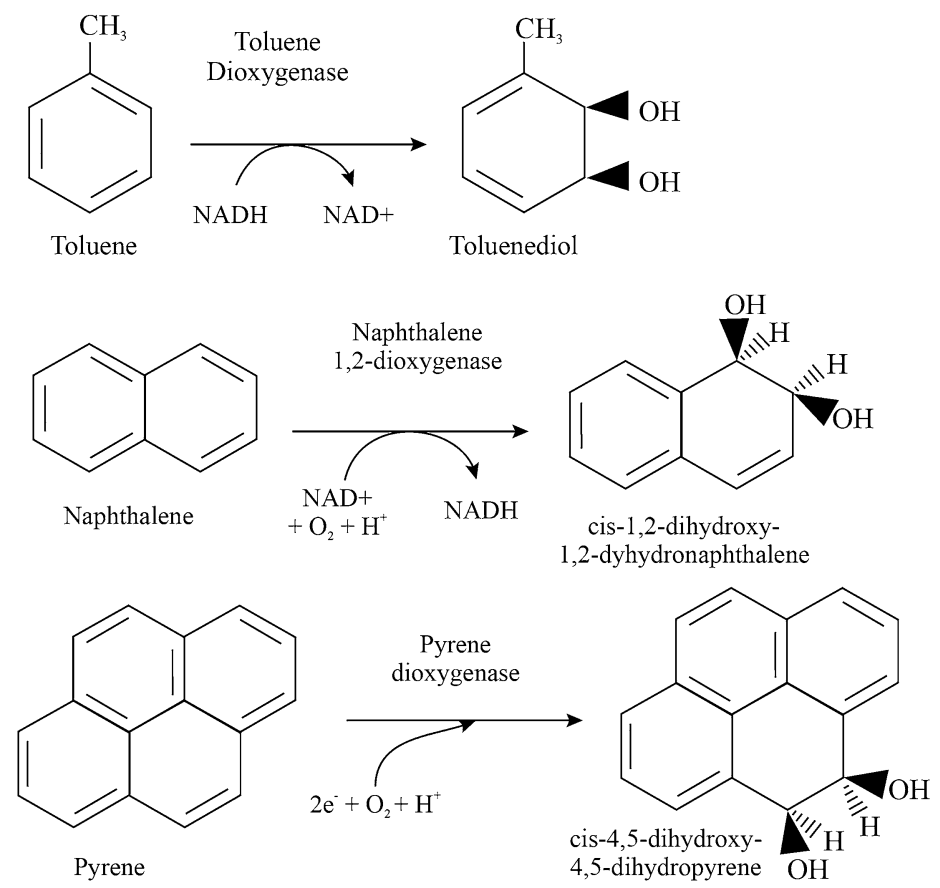

Fig. 3 Formation of cis-dihydrodiols of toluene, naphthalene and pyrene catalyzed by diooxygenases

A group named Rieske non-heme iron-dependent oxygenase systems, also important in aromatic hydrocarbon oxidation, are NADH-dependent and composed of a flavoprotein reductase, an iron-sulfur ferredoxin, and an iron-sulfur ferredoxin as catalytic component (Barry and Challis 2013; Ferraro et al. 2005).

The upper pathways begin with an oxidation and finish with the formation of central intermediates, which can be catechols or non-catecholic compounds (Fig. 4). The former have cis-dihydrodiols groups (Ma et al. 2013; Tao et al. 2005) and latter are hydroxy-substituted aromatic carboxylic acids (Fetzner 2012) resulting from reactions catalyzed by monooxygenases and dioxygenases.

Catechol was found by Loh and Chua (2002) evaluating the ability of P. putida ATCC 49451 to degrade sodium benzoate. Catechol was also reported by Karigar et al. (2006) as an intermediate of the phenol metabolic pathway by Arthrobacter citreus. (Chloro)hydroxyquinol was reported by Pérez-Pantoja et al. (2008) as a central intermediate of 2,4,6 trichlorophenol degradation by Cupriavidus necator JMP134. It was also reported by Khan et al. (2013) in the metabolism of 2-chloro4-nitroaniline by Rhodococcus sp. Strain MB-P1. In the metabolism of paranitrophenol in Pseudomonas sp. strain 1-7, Zhang et al. (2012a, b) found the hydroquinone and hydroxyhydroquinone as central intermediates.

The central intermediates that are non-catechols are hydroxy-substituted aromatic carboxylic acids (Fetzner 2012) (Fig. 4). Among the intermediates reported are the gentisate found by Romero-Silva et al. (2013) studying the peripheral pathways of 3-hydroxybenzoate and 4-hydroxybenzoate degradation by Burkholderia xenovorans LB400. Protocatechuate was reported by Kim et al. (2006) as an intermediate in 
a<smiles>Oc1ccccc1O</smiles><smiles>Oc1cc(O)c(Cl)cc1O</smiles>

1<smiles>Oc1ccc(O)cc1</smiles>

3
2<smiles>CO</smiles><smiles>Cc1ccc(O)cc1O</smiles>

4 b

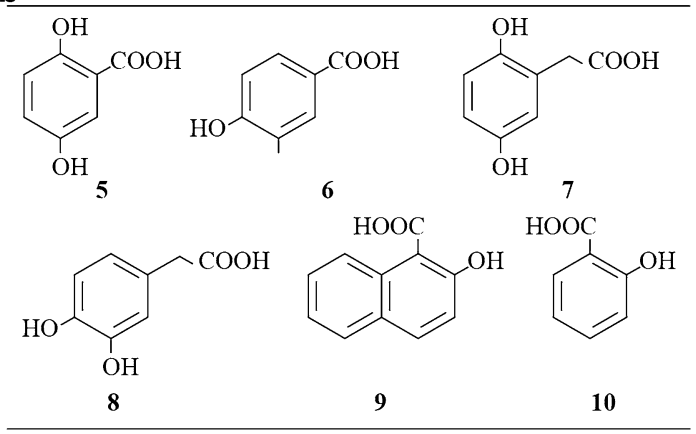

Fig. 4 Central intermediates formed in upper pathway under aerobic conditions. (a) Dihydrodiols (1) Hydroquinone, (2) Catechol, (3) (Chloro)hydroxyquinol, (4) Hydroxyhydroquinone, (b) hydroxy-substituted aromatic carboxylic acids, (5) Gentisate, (6) Protocatechuate, (7) Homogentisate, (8) Homoprotocatechuate, (9) 2-hydroxy-1-naphtoic acid, (10) Salicylic acid

the metabolism of para-hydroxybenzoate and vanilline in P. putida KT2440. The homogentisate and homoprotocatechuate were reported by Méndez et al. (2011) in studies with Burkholderia xenovorans LB400 degrading 3-hydroxybenzoate.

2-Hydroxy-1-naphtoic acid and salicylic acid were reported by Mallick and Dutta (2008) studying naphthalene degradation by Staphylococcus sp. strain PN/Y. The 3-hydroxyanthranilate was reported by Hasegawa et al. (2000) as part of degradative pathway of 2-nitrobenzoate by P. fluorescens strain KU-7.

The lower pathways refer to the dearomatization of central intermediates and ring cleavage to tricarboxylic acids (Fig. 5). The first reaction of lower pathways comprises of the de-aromatization of central intermediates, which, thereafter, undergo ortho-, meta- or para-cleavage by dioxygenases (Harwood and Parales 1996). Orthocleavage, also known as the $\beta$-ketoadipate pathway, is between two hydroxyl groups and catalyzed by intradiol-type dioxygenases using Fe(II) as cofactor (Guzik et al. 2013). Meta-cleavage is on the carbon-carbon bond adjacent to the hydroxyl groups through the formation of an $\alpha$-keto-lactone intermediate, catalyzed by extradiol-type dioxygenases, using Fe(III) as cofactor (Suenaga et al. 2014). Ortho cleavage of the catechol ring is catalyzed by catechol 1,2-dioxygenase to cis,cis-muconate; catechol meta-cleavage is catalyzed by catechol 2,3-dioxygenase to 2-hydroxy-muconic semialdehyde. Both cleavage pathways were reported by Loh and Chua (2002) in benzoate degradation by $P$. putida. The para-cleavage pathway is followed in hydroxy-substituted aromatic carboxylic acids between the carboxyl-substituted and the adjacent hydroxylated carbon atom. This para-cleavage pathway was reported by Dagley (1971) catalyzed by 2,3-gentisate dioxygenase to gentisate. Crawford (1975) also reported para-cleavage to protocatechuate, catalyzed by 2,3-protocatechuate dioxygenase in Bacillus circulans metabolizing 4-hydroxyphenyl propionic acid.

The ring cleavage, of hydroxy-substituted aromatic carboxylic acids, is catalyzed by enzymes that belong to the cupin superfamily. Most cupin-type ring cleavage dioxygenases use an $\mathrm{Fe}(\mathrm{II})$ center for catalysis and an action mechanism similar to extradiol dioxygenases (Fetzner 2012). 


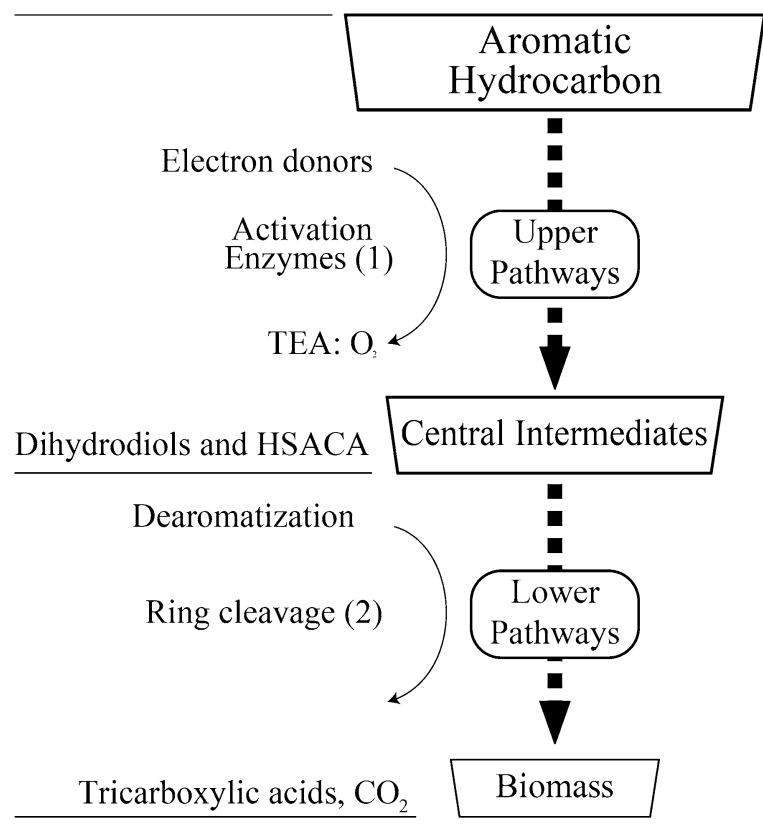

Fig. 5 Schematic representation of metabolic pathways of aromatic hydrocarbons by bacteria under aerobic conditions. Upper pathways are through hydrocarbon molecule to central intermediates. Lower pathways go from destabilization of central intermediates to biomass yield. Electron donors: $\mathrm{NAD}(\mathrm{P}) \mathrm{H}, \mathrm{FMNH}_{2}$ or $\mathrm{FADH}_{2}$, ferredoxin, NADH. TEA terminal electron acceptor, Dihydrodiols = catechol, (chloro)catechol, (nitro)catechol, (chloro)hydroxyquinol, hydroquinone, hydroxyhydroquinone, (1) Mooxygenases or dioxygenases enzymes. HSACA (hydroxysubstituted aromatic carboxylic acids) $=$ gentisate, protocatechuate, homogentisate, homoprotocatechuate, 2-hydroxy-1-naphtoic acid, salicylic acid, 3-hydroxyanthranilate

\subsection{Aromatic Hydrocarbon Biodegradation Under Anaerobic Conditions}

In the absence of oxygen, oxidized inorganic compounds such as nitrate $\left(\mathrm{NO}_{3}{ }^{-1}\right)$, manganese $(\mathrm{Mn}(\mathrm{IV}))$, iron ( $\mathrm{Fe}(\mathrm{III}))$, sulfate $\left(\mathrm{SO}_{4}{ }^{-2}\right)$ and carbon dioxide $\left(\mathrm{CO}_{2}\right)$ act as the terminal electron acceptors (TEAs) (Fuchs et al. 2011; Vogt et al. 2011). The methanogenic reduction also plays an important role in anaerobic biodegradation, particularly at sites that have been contaminated for longer periods of time where other TEAs have been depleted (Lovley 1997).

Most studies reported that, under anaerobic conditions, activation in the upper pathways is by a reduction catalyzed by synthases, dehydrogenases and carboxylases (Chakraborty and Coates 2005; Heider 2007; Meckenstock and Mouttaki 2011). However, Philipp and Schink (1998) reported evidence of two oxidative reactions as the activation reaction in anaerobic degradation of resorcinol. 
1

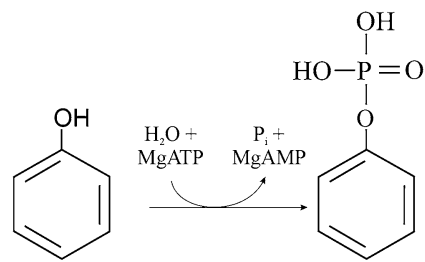

Phenol

3

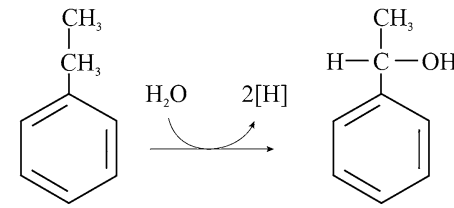

Ethylbenzene

5

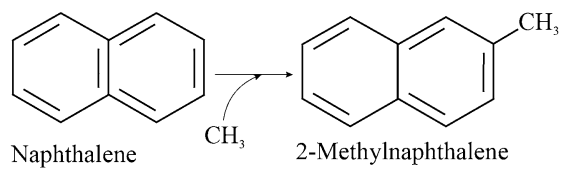

2

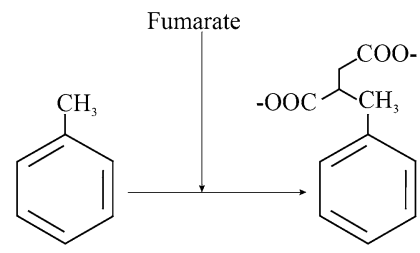

Toluene

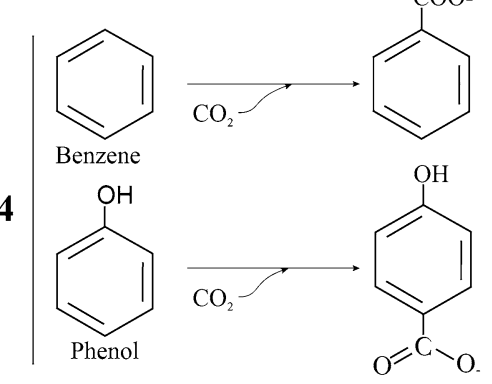

Fig. 6 The current five activation ways studied as the first step of upper pathways under anaerobic conditions. (1) Phosphorylation, (2) Fumarate insertion, (3) $\mathrm{O}_{2}$-independente hydroxylation, (4) Carboxylation, (5) Methylation. Phenol can be phosphorylated or carboxylated

Currently, the following five ways of activation of aromatic hydrocarbons activation are being discussed: (1) Phosphorylation. Activation occurs by insertion of a phosphate group. In the case of phenol in Tauera aromatica catalysis occurs by a phenylphosphate synthase (Narmandakh et al. 2006; Schmeling et al. 2004). (2) Fumarate insertion. Alkylated aromatic hydrocarbons such as toluene, cresols and xylenes are activated by radical-based addition of a fumarate to the methyl group and, in the case of ethylbenzene onto the side chain (Heider 2007). (3) O2independent hydroxylation. Vogel and Grbìc-Galìc (1986) using partially ${ }^{18} \mathrm{O}-$ labelled water in an enrichment culture in methanogenic incubations presented toluene and benzene hydroxylation indicating that the hydroxyl group originated from water. Johnson et al. (2001) showed that an ethylbenzene dehydrogenase in Azoarcus sp. strain EB1 catalyzes the insertion of one hydroxyl group onto ethylbenzene to produce (S)-(-)-1-phenylethanol (Fig. 6). (4) Carboxylation. Also called the "biological Kolbe-Schmitt reaction", the carboxylation reaction has been suggested for monoaromatic hydrocarbons and non-substituted PAHs as follows. The carboxylation of phenol in para-position yielding 4-hydroxybenzoate by strains K172 and S100 was proposed by Tschech and Fuchs (1987). Zhang and Young (1997) working with enrichment cultures with $\left[{ }^{13} \mathrm{C}\right]$ bicarbonate and sulfate reducing conditions found 2-naphthoate and phenanthrene carboxylic acid indicating that naphthalene and phenanthrene carboxylation. (5) Methylation. Also called Friedel-Crafts-type methylation, it was reported by Safinowski and Meckenstock (2006) as the initial reaction in the anaerobic degradation of naphthalene by sulfate-reducing enrichment cultures. Mouttaki et al. (2012) reported the methylation of naphthalene as the first breakdown reaction by enrichment culture N47 in sulphate-reducing conditions. 
Fig. 7 Central intermediates of anaerobic biodegradation of aromatic hydrocarbons. (1) Benzoyl-CoA, (2) 3-methylbenzoyl-CoA, (3) 3-hydroxybenzoyl-CoA, (4)

2-amino-benzoyl-CoA, (5)

Phloroglucinol, (6)

Resorcinol, (7)

Hydroxyhydroquinone

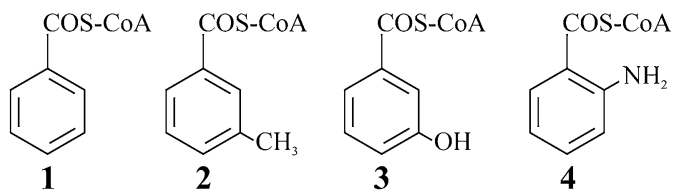<smiles>Oc1cc(O)cc(O)c1</smiles>

The upper pathways are characterized by different metabolic pathways with several central intermediates, here we review seven of them (Fig. 7). The most common is benzoyl-CoA with 2-amino, 3-hydroxy and 3-methyl derivatives (Boll and Fuchs 1995; Koch and Fuchs 1992; Laempe et al. 1999; Merkel et al. 1989; Philipp and Schink 2012). Resorcinol was reported by Boyd et al. (1983) in studies of degradation of several aromatic hydrocarbons. Phloroglucinol was reported by Brune et al. (1992) as the intermediate in the metabolism of pyrogallol by Pelobacter massiliensis. Hydroxyhydroquinone (HHQ) was reported in the nitrate-reducing bacterium Azoarcus anaerobius strain LuFRes1 from hydroxylation of resorcinol (Philipp and Schink 1998).

The lower pathways begin with dearomatization of the central intermediates and can be by reductive or oxidative reactions throughout as will be described below.

Dearomatization of benzoyl-CoA is catalyzed by benzoyl-CoA reductase that seems to follow a Birch-like mechanism to yield cyclohexadiene-carbonyl-CoA (1,5-dienoyl-CoA).

Two classes of benzoyl-CoA reductases (BCR) have been reported. Class I BCR is ATP-consuming and found in facultative microorganisms (Boll and Fuchs 1995; Egland et al. 1997) and class II BCR is found in strictly anaerobic microorganisms being ATP-independent (Holmes et al. 2012). Both classes of BCR produce 1,5-dienoyl-CoA. However, when class I BCR catalyzes, the reaction requires one molecule of the reduced protein ferredoxin as electron donor $\left(E^{\circ}=-420 \mathrm{mV}\right)$, two molecules of ATP and two molecules of water (Boll and Fuchs 1995). The electron donor for class II BCR is unknown (Holmes et al. 2012).

For the de-aromatization of resorcinol (1,3-dihydrobenzene), two different pathways have been reported. The first is a reductive reaction as reported by Tschech and Schink (1985) and by Kluge et al. (1990) in Clostridium sp. and Campylobacter sp. co-culture named KN245, catalyzed by a resorcinol reductase yielding 1,3 cyclohexanedione. The second one, is an oxidative reaction releasing hydroxyhydroquinone (HHQ) described for the nitrate reducing bacterium Azoarcus anaerobius strain LuFRes1 (Philipp and Schink 1998).

De-aromatization of phloroglucinol had been studied in detail with Eubacterium oxidoreducens and Pellobacter acidigallici. This compound is reduced to dihydrophloroglucinol by an NADPH-dependent reductase (Armstrong and Patel 1994; Boll 2005; Brune and Schink 1992). 
There are three metabolic pathways to de-aromatize Hydroxyhydroquinone (HHQ). The isomerization to phloroglucinol by the fermentative bacterium Pellobacter massiliensis (Brune et al. 1992), the reduction to dihydro-HHQ was observed with the sulfate reducing bacterium Desulfovibrio inopinatus (Philipp and Schink 2012) and an oxidative degradation to 2-hydroxy-1,4-benzoquinone by the nitrate-reducing bacterium Azoarcus anaerobius strain LuFRes1 (Philipp and Schink 1998).

The ring cleavage is a reductive step of the lower pathways. Benzoyl-CoA is transformed to 6-oxo-2-hydroxycyclo-hexane-1-carboxyl-CoA that still maintains the carbon ring. Fission of this ring is catalyzed by the 6-oxo-2-hydroxycyclohexane-1-carboxyl-CoA hydrolase using one molecule of water to produce 3-hydroxypimelyl-CoA (UM-BBD 2015).

Philipp and Schink (2012) reported that 1,3-cyclohexadione, a reductive intermediate of resorcinol, is hydrolytically cleaved to 5-oxocaproic acid that is breakdown to an acetate and a butyrate.

Dihydroxyphloroglucinol, originated from phloroglucinol de-aromatization, is cleaved hydrolytically yielding 3-hydroxy-5-oxohexanoic acid, which is then oxidized to triacetic acid (3,5-dioxohexanoic acid) (Brune and Schink 1992).

The first reaction for ring cleavage of HHQ is an oxidation catalyzed by a membrane-bound HHQ-dehydrogenase and then channeled to acetate, malate and succinate (Darley et al. 2007) (Fig. 8). Information about particular compounds undergoing ring cleavage was not found.

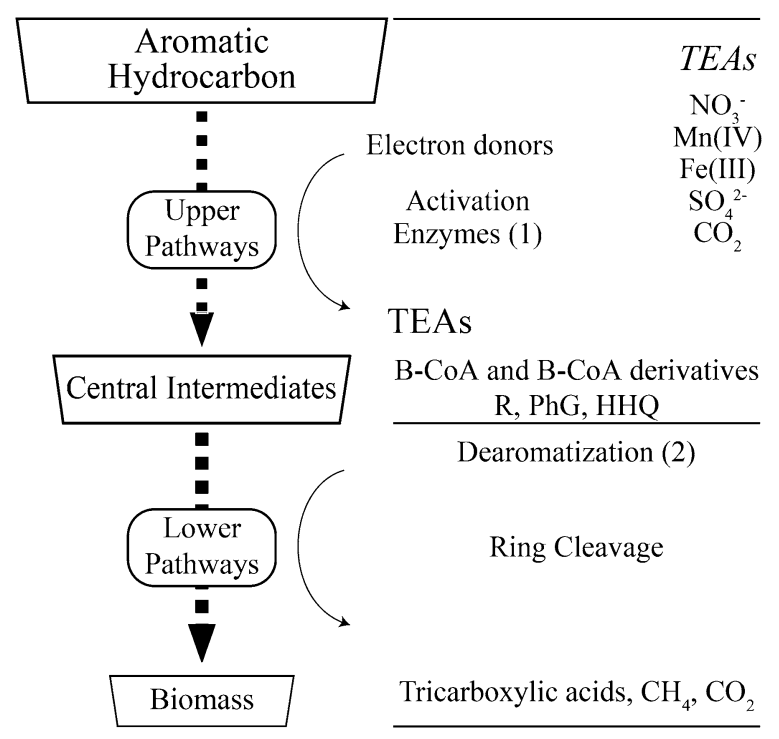

Fig. 8 Schematic representation of upper and lower pathways of aromatic hydrocarbon degradation under anaerobic conditions by bacteria. Electron donors: NAD(P)H, Ferredoxin. Enzymes (1): Synthases, Carboxylases, Dehydrogenases. B-Coa: Benzoyl-CoA; B-CoA derivatives are 2-amino benzoyl-CoA, 3-hydroxy benzoyl-CoA, 4-methyl benzoyl-CoA. $R$ resorcinol, $P h G$ phloroglucinol, $H H Q$ hydroxyhydroquinone. dearomatization (2) is the initial step of lower pathway 


\section{Practical Applications of Knowledge About Metabolic Pathways}

The knowledge about the metabolism of aromatic hydrocarbons could result in environmentally-friendly practical applications. The cleanup of pollutants by bioaugmentation (introducing bacteria from external sites), and/or biostimulation (providing nutrients or electron acceptors stimulating native populations) in natural or enhanced conditions are the best-known techniques (Prince 2010).

The 1,2- and 1,3-cyclohexanedione, derivatives of the metabolism of resorcinol are cyclic b-triketones able to inactivate toxin A (enterotoxin) and toxin B (cytotoxin) of $C$. difficile with a promising use in medicine (Balfanz and Rautenberg 1989). Their food, antibiotic, antimalarial, antidiabetic and anticancer therapeutical properties have also been reviewed (Blanco et al. 2003).

Muconic acid obtained from the ortho-cleavage of catechol has potential applications in the production of resins, bio-plastics, food additives, agrochemicals and pharmaceuticals (Xie et al. 2014). Lin et al. (2014) devised a novel artificial pathway for the efficient production of muconic acid based on the salicylic acid degradation pathway.

\section{Summary}

The aim of this review was to build an updated collection of information focused on the mechanisms and elements involved in metabolic pathways of aromatic hydrocarbons by bacteria. Enzymes as an expression of the genetic load and the type of electron acceptor available, as an environmental factor, were highlighted. In general, the review showed that both aerobic routes and anaerobic routes for the degradation of aromatic hydrocarbons are divided into two pathways. The first, named the upper pathways, entails the route from the original compound to central intermediate compounds still containing the aromatic ring but with the benzene nucleus chemically destabilized. The second, named the lower pathway, begins with ring de-aromatization and subsequent cleavage, resulting in metabolites that can be used by bacteria in the production of biomass. Under anaerobic conditions the five mechanisms of activation of the benzene ring described show the diversity of chemical reactions that can take place. Obtaining carbon and energy from an aromatic hydrocarbon molecule is a process that exhibits the high complexity level of the metabolic apparatus of anaerobic microorganisms. The ability of these bacteria to express enzymes that catalyze reactions, known only in non-biological conditions, using final electron acceptors with a low redox potential, is a most interesting topic. The discovery of phylogenetic and functional characteristics of cultivable and noncultivable hydrocarbon degrading bacteria has been made possible by improvements in molecular research techniques such as SIP (stable isotope probing) tracing the incorporation of ${ }^{13} \mathrm{C},{ }^{15} \mathrm{~N}$ and ${ }^{18} \mathrm{O}$ into nucleic acids and proteins. 
Since many metabolic pathways in which enzyme and metabolite participants are still unknown, much new research is required. Therefore, it will surely allow enhancing the known and future applications in practice.

Acknowledgements We thank the CNPq (Conselho Nacional de Desenvolvimento Científico e Tecnológico) for their financial support with grant 870102/2011-7 and the Universidade Estadual Paulista-UNESP—campus São José do Rio Preto where this work and other research are being developed.

\section{References}

Aanderud ZT, Lennon JT (2011) Validation of heavy-water stable isotope probing for the characterization of rapidly responding soil bacteria. Appl Env Microbiol 4589-4596. doi:10.1128/ aem.02735-10

Abu Laban N, Tan B, Dao A, Foght J (2015) Draft genome sequence of uncultivated Desulfosporosinus sp. strain Tol-M, obtained by stable isotope probing using [13C6]toluene. Genome Announ doi:10.1128/genomeA.01422-14

Armstrong SM, Patel TR (1994) Microbial degradation of phloroglucinol and other polyphenolic compounds. J Basic Microbiol 123-135. doi:10.1002/jobm.3620340208

Balfanz J, Rautenberg P (1989) Inhibition of Clostridium difficile toxin A and B by 1,2-cyclohexanedione modification of an arginine residue. Biochem Biophys Res Commun 1364-1370. doi:10.1016/0006-291X(89)92754-X

Barry SM, Challis GL (2013) Mechanism and catalytic diversity of rieske non-heme irondependent oxygenases. ACS Catal 2362-2370. doi:10.1021/cs400087p

Blanco CA, Caballero I, Rojas A, Gomez M, Alvarez J (2003) Chelation of aqueous iron(III) by 2-acetyl-1,3-cyclohexanedione and beer ageing. Food Chem 561-568. doi:10.1016/ S0308-8146(02)00491-0

Boll M (2005) Dearomatizing benzene ring reductases. J Mol Microbiol Biotechnol 132-142. doi: $10.1159 / 000091560$

Boll M, Fuchs G (1995) Benzoyl-coenzyme A reductase (dearomatizing), a key enzyme of anaerobic aromatic metabolism. Eur J Biochem 921-933. doi:10.1111/j.1432-1033.1995.921_a.x

Boyd SA, Shelton DR, Berry D, Tiedje JM (1983) Anaerobic biodegradation of phenolic compounds in digested sludge. Appl Environ Microbiol 50-54. doi:http://aem.asm.org/content/46/1/50.abstract

Bruice PY (2004) Organic Chemistry. Prentice Hall, Upper Saddle River, NJ

Brune A, Schink B (1992) Phloroglucinol pathway in the strictly anaerobic Pelobacter acidigallici: fermentation of trihydroxybenzenes to acetate via triacetic acid. Arch Microbiol 417-424. doi:10.1007/BF00249098

Brune A, Schnell S, Schink B (1992) Sequential transhydroxylations converting hydroxyhydroquinone to phloroglucinol in the strictly anaerobic, fermentative bacterium Pelobacter massiliensis. Appl Environ Microbiol 1861-1868. doi:http://aem.asm.org/content/58/6/1861.abstract

Cafaro V, Izzo V, Scognamiglio R, Notomista E, Capasso P, Casbarra A, Pucci P, Di Donato A (2004) Phenol hydroxylase and toluene/o-xylene monooxygenase from Pseudomonas stutzeri OX1: interplay between two enzymes. Appl Environ Microbiol 2211-2219. doi:10.1128/ aem.70.4.2211-2219.2004

Carmona M, Zamarro MT, Blázquez B, Durante-Rodríguez G, Juárez JF, Valderrama JA, Barragán MJL, García JL, Díaz E (2009) Anaerobic catabolism of aromatic compounds: a genetic and genomic view. Microbiol Mol Biol Rev 71-133. doi:10.1128/mmbr.00021-08

Chakraborty R, Coates JD (2005) Hydroxylation and carboxylation-two crucial steps of anaerobic benzene degradation by dechloromonas strain RCB. Appl Env Microbiol 5427-5432. doi:10.1128/aem.71.9.5427-5432.2005 
Crawford RL (1975) Novel pathway for degradation of protocatechuic acid in Bacillus species. J Bacteriol 531-536. doi:http://jb.asm.org/content/121/2/531.abstract

Cupples AM (2011) The use of nucleic acid based stable isotope probing to identify the microorganisms responsible for anaerobic benzene and toluene biodegradation. J Microbiol Methods 83-91. doi:10.1016/j.mimet.2011.02.011

Dagley S (1971) Catabolism of aromatic compounds by micro-organisms. In: Rose AH, Wilkinson JF (eds) Advances in microbial physiology. Academic, Waltham, MA, pp 1-46

Darley PI, Hellstern JA, Medina-Bellver JI, Marqués S, Schink B, Philipp B (2007) Heterologous expression and identification of the genes involved in anaerobic degradation of 1,3-dihydroxybenzene (resorcinol) in Azoarcus anaerobius. J Bacteriol 3824-3833. doi:10.1128/jb.01729-06

DeLaune RD, Reddy KR (2005) REDOX POTENTIAL. In: Hillel D (ed) Encyclopedia of soils in the environment. Elsevier, Oxford, pp 366-371

Díaz E, Jiménez JI, Nogales J (2013) Aerobic degradation of aromatic compounds. Curr Opin Biotechnol 431-442. doi:10.1016/j.copbio.2012.10.010

Egland PG, Pelletier DA, Dispensa M, Gibson J, Harwood CS (1997) A cluster of bacterial genes for anaerobic benzene ring biodegradation. Proc Natl Acad Sci 6484-6489. doi:http://www. pnas.org/content/94/12/6484.abstract

Favre HA, Powell WH (2013) Nomenclature of organic chemistry. IUPAC recommendations and preferred names. Royal Society of Chemistry, Cambridge

Ferraro DJ, Gakhar L, Ramaswamy S (2005) Rieske business: structure-function of Rieske nonheme oxygenases. Biochem Biophys Res Commun 175-190. doi:10.1016/j.bbrc.2005.08.222

Fetzner S (2012) Ring-cleaving dioxygenases with a cupin fold. Appl Env Microbiol 2505-2514. doi:10.1128/aem.07651-11

Fuchs G, Boll M, Heider J (2011) Microbial degradation of aromatic compounds-from one strategy to four. Nat Rev Microbiol 803-816. doi:10.1038/nrmicro2652

Ghosh S, Chisti Y, Banerjee UC (2012) Production of shikimic acid. Biotechnol Adv 1425-1431. doi:10.1016/j.biotechadv.2012.03.001

Gibson JS, Harwood C (2002) Metabolic diversity in aromatic compound utilization by anaerobic microbes. Annu Rev Microbiol 345-369. doi:10.1146/annurev.micro.56.012302.160749

Guzik U, Hupert-Kocurek K, Wojcieszyńska D (2013) Intradiol dioxygenases - the key enzymes in xenobiotics degradation.

Hareland WA, Crawford RL, Chapman PJ, Dagley S (1975) Metabolic function and properties of 4-hydroxyphenylacetic acid 1-hydroxylase from Pseudomonas acidovorans. J Bacteriol 272 285. doi:http://jb.asm.org/content/121/1/272.abstract

Harwood CS, Parales RE (1996) The $\beta$-ketoadipate pathway and the biology of self-identity. Annu Rev Microbiol 553-590. doi:10.1146/annurev.micro.50.1.553

Hasegawa Y, Muraki T, Tokuyama T, Iwaki H, Tatsuno M, Lau PCK (2000) A novel degradative pathway of 2-nitrobenzoate via 3-hydroxyanthranilate in Pseudomonas fluorescens strain KU-7. FEMS Microbiol Lett 185-190. doi:http://femsle.oxfordjournals.org/content/190/2/185. abstract

Heider J (2007) Adding handles to unhandy substrates: anaerobic hydrocarbon activation mechanisms. Curr Opin Chem Biol 188-194. doi:10.1016/j.cbpa.2007.02.027

Holmes DE, Risso C, Smith JA, Lovley DR (2012) Genome-scale analysis of anaerobic benzoate and phenol metabolism in the hyperthermophilic archaeon Ferroglobus placidus. ISME J 146157. doi:http://www.nature.com/ismej/journal/v6/n1/suppinfo/ismej201188s1.html

Huijbers MME, Montersino S, Westphal AH, Tischler D, van Berkel WJH (2014) Flavin dependent monooxygenases. Arch Biochem Biophys 2-17. doi:10.1016/j.abb.2013.12.005

Johnson HA, Pelletier DA, Spormann AM (2001) Isolation and characterization of anaerobic ethylbenzene dehydrogenase, a novel Mo-Fe-S enzyme. J Bacteriol 4536-4542. doi:10.1128/ jb.183.15.4536-4542.2001

Karickhoff SW (1981) Semi-empirical estimation of sorption of hydrophobic pollutants on natural sediments and soils. Chemosphere 833-846. doi:10.1016/0045-6535(81)90083-7 
Karigar C, Mahesh A, Nagenahalli M, Jin D (2006) Phenol degradation by immobilized cells of Arthrobacter citreus. Biodegradation 47-55. doi:10.1007/s10532-005-3048-y

Khan F, Pal D, Vikram S, Cameotra SS (2013) Metabolism of 2-chloro-4-nitroaniline via novel aerobic degradation pathway by Rhodococcus sp. strain MB-P1. PLoS ONE e62178. doi:10.1371/journal.pone.0062178

Kim YH, Cho K, Yun S-H, Kim JY, Kwon K-H, Yoo JS, Kim SI (2006) Analysis of aromatic catabolic pathways in Pseudomonas putida KT 2440 using a combined proteomic approach: 2-DE/MS and cleavable isotope-coded affinity tag analysis. Proteomics 1301-1318. doi:10.1002/pmic.200500329

Kim S-J, Park S-J, Cha I-T, Min D, Kim J-S, Chung W-H, Chae J-C, Jeon CO, Rhee S-K (2014) Metabolic versatility of toluene-degrading, iron-reducing bacteria in tidal flat sediment, characterized by stable isotope probing-based metagenomic analysis. Environ Microbiol 189-204. doi:10.1111/1462-2920.12277

Kleinsteuber S, Schleinitz K, Vogt C (2012) Key players and team play: anaerobic microbial communities in hydrocarbon-contaminated aquifers. Appl Microbiol Biotechnol 851-873. doi:10.1007/s00253-012-4025-0

Kluge C, Tschech A, Fuchs G (1990) Anaerobic metabolism of resorcyclic acids (m-dihydroxybenzoic acids) and resorcinol (1,3-benzenediol) in a fermenting and in a denitrifying bacterium. Arch Microbiol 68-74. doi:10.1007/BF00291277

Koch J, Fuchs G (1992) Enzymatic reduction of benzoyl-CoA to alicyclic compounds, a key reaction in anaerobic aromatic metabolism. Eur J Biochem 195-202. doi:10.1111/j.1432-1033.1992. tb16768.x

Laempe D, Jahn M, Fuchs G (1999) 6-Hydroxycyclohex-1-ene-1-carbonyl-CoA dehydrogenase and 6-oxocyclohex-1-ene-1-carbonyl-CoA hydrolase, enzymes of the benzoyl-CoA pathway of anaerobic aromatic metabolism in the denitrifying bacterium Thauera aromatica. Eur $\mathbf{J}$ Biochem 420-429. doi:10.1046/j.1432-1327.1999.00504.x

Li X, Chapple C (2010) Understanding lignification: challenges beyond monolignol biosynthesis. Plant Physiol 449-452. doi:10.1104/pp.110.162842

Lin Y, Sun X, Yuan Q, Yan Y (2014) Extending shikimate pathway for the production of muconic acid and its precursor salicylic acid in Escherichia coli. Metab Eng 62-69. doi:10.1016/j. ymben.2014.02.009

Loh K-C, Chua S-S (2002) Ortho pathway of benzoate degradation in Pseudomonas putida: induction of meta pathway at high substrate concentrations. Enzyme Microb Technol 620-626. doi:10.1016/S0141-0229(02)00016-9

Lovley DR (1997) Potential for anaerobic bioremediation of BTEX in petroleum-contaminated aquifers. J Ind Microbiol Biotechnol 75-81. doi:10.1038/sj.jim.2900246

Ma F, Shi S-N, Sun T-H, Li A, Zhou J-T, Qu Y-Y (2013) Biotransformation of benzene and toluene to catechols by phenol hydroxylase from Arthrobacter sp. W1. Appl Microbiol Biotechnol 5097-5103. doi:10.1007/s00253-012-4301-z

Mallick S, Dutta TK (2008) Kinetics of phenanthrene degradation by Staphylococcus sp. strain $\mathrm{PN} / \mathrm{Y}$ involving 2-hydroxy-1-naphthoic acid in a novel metabolic pathway. Process Biochem 1004-1008. doi:10.1016/j.procbio.2008.04.022

Meckenstock RU, Mouttaki H (2011) Anaerobic degradation of non-substituted aromatic hydrocarbons. Curr Opin Biotechnol 406-414. doi:10.1016/j.copbio.2011.02.009

Méndez V, Agulló L, González M, Seeger M (2011) The homogentisate and homoprotocatechuate central pathways are involved in 3- and 4-hydroxyphenylacetate degradation by Burkholderia xenovorans LB400. PLoS ONE e17583. doi:10.1371/journal.pone.0017583

Merkel SM, Eberhard AE, Gibson J, Harwood CS (1989) Involvement of coenzyme A thioesters in anaerobic metabolism of 4-hydroxybenzoate by Rhodopseudomonas palustris. J Bacteriol 1-7. doi:http://jb.asm.org/content/171/1/1.abstract

Mouttaki H, Johannes J, Meckenstock RU (2012) Identification of naphthalene carboxylase as a prototype for the anaerobic activation of non-substituted aromatic hydrocarbons. Environ Microbiol 2770-2774. doi:10.1111/j.1462-2920.2012.02768.x 
Narmandakh A, Gad'on N, Drepper F, Knapp B, Haehnel W, Fuchs G (2006) Phosphorylation of Phenol by phenylphosphate synthase: role of histidine phosphate in catalysis. J Bacteriol 7815-7822. doi:10.1128/jb.00785-06

Parales R, Resnick S (2004) Aromatic hydrocarbon dioxygenases. In: Singh A, Ward O (eds) Biodegradation and bioremediation. Springer, Berlin, pp 175-195

Pérez-Pantoja D, De la Iglesia R, Pieper DH, González B (2008) Metabolic reconstruction of aromatic compounds degradation from the genome of the amazing pollutant-degrading bacterium CupriavidusnecatorJMP134.FEMSMicrobiolRev736-794.doi:10.1111/j.1574-6976.2008.00122.x

Philipp B, Schink B (1998) Evidence of two oxidative reaction steps initiating anaerobic degradation of resorcinol (1,3-dihydroxybenzene) by the denitrifying bacterium Azoarcus anaerobius. J Bacteriol 3644-3649. doi:http://jb.asm.org/content/180/14/3644.abstract

Philipp B, Schink B (2012) Different strategies in anaerobic biodegradation of aromatic compounds: nitrate reducers versus strict anaerobes. Environ Microbiol Rep 469-478. doi:10.1111/j.1758-2229.2011.00304.x

Pilloni G, von Netzer F, Engel M, Lueders T (2011) Electron acceptor-dependent identification of key anaerobic toluene degraders at a tar-oil-contaminated aquifer by Pyro-SIP. FEMS Microbiol Ecol 165-175. doi:10.1111/j.1574-6941.2011.01083.x

Prince RC (2010) Bioremediation of marine oil spills. In: Timmis K (ed) Handbook of hydrocarbon and lipid microbiology. Springer, Berlin, pp 2617-2630

Rettedal EA, Brözel VS (2015) Characterizing the diversity of active bacteria in soil by comprehensive stable isotope probing of DNA and RNA with H218O. Microbiol Open 208-219. doi:10.1002/mbo3.230

Romero-Silva MJ, Méndez V, Agulló L, Seeger M (2013) Genomic and functional analyses of the gentisate and protocatechuate ring-cleavage pathways and related 3-hydroxybenzoate and 4-hydroxybenzoate peripheral pathways in Burkholderia xenovorans LB400. PLoS ONE e56038. doi:10.1371/journal.pone.0056038

Safinowski M, Meckenstock RU (2006) Methylation is the initial reaction in anaerobic naphthalene degradation by a sulfate-reducing enrichment culture. Environ Microbiol 347-352. doi:10.1111/j.1462-2920.2005.00900.x

Schink B, Philipp B, Müller J (2000) Anaerobic degradation of phenolic compounds. Naturwissenschaften 12-23. doi:10.1007/s001140050002

Schmeling S, Narmandakh A, Schmitt O, Gad'on N, Schühle K, Fuchs G (2004) Phenylphosphate synthase: a new phosphotransferase catalyzing the first step in anaerobic phenol metabolism in Thauera aromatica. J Bacteriol 8044-8057. doi:10.1128/jb.186.23.8044-8057.2004

Staats M, Braster M, Röling WFM (2011) Molecular diversity and distribution of aromatic hydrocarbon-degrading anaerobes across a landfill leachate plume. Environ Microbiol 12161227. doi:10.1111/j.1462-2920.2010.02421.x

Suenaga H, Mizuta S, Miyazaki K, Yaoi K (2014) Diversity of extradiol dioxygenases in aromaticdegrading microbial community explored using both culture-dependent and cultureindependent approaches. FEMS Microbiol Ecol 367-379. doi:http://femsec.oxfordjournals. org/content/90/2/367.abstract

Tao Y, Bentley WE, Wood TK (2005) Regiospecific oxidation of naphthalene and fluorene by toluene monooxygenases and engineered toluene 4-monooxygenases of Pseudomonas mendocina KR1. Biotechnol Bioeng 85-94. doi:10.1002/bit.20414

Taubert M, Vogt C, Wubet T, Kleinsteuber S, Tarkka MT, Harms H, Buscot F, Richnow H-H, von Bergen M, Seifert J (2012) Protein-SIP enables time-resolved analysis of the carbon flux in a sulfate-reducing, benzene-degrading microbial consortium. ISME J 2291-2301. doi:http:// www.nature.com/ismej/journal/v6/n12/suppinfo/ismej201268s1.html

Tschech A, Fuchs G (1987) Anaerobic degradation of phenol by pure cultures of newly isolated denitrifying pseudomonads. Arch Microbiol 213-217. doi:10.1007/BF00414814

Tschech A, Schink B (1985) Fermentative degradation of resorcinol and resorcylic acids. Arch Microbiol 52-59. doi:10.1007/BF00414768 
UM-BBD (2015) Biocatalysis/biodegradation database (on line). University of Minnesota, Minneapolis, MN

USEPA (ed) (2005) Guidelines for carcinogen risk assessment. United States Environmental Protection Agency, Washington, DC

Vogel TM, Grbìc-Galìc D (1986) Incorporation of oxygen from water into toluene and benzene during anaerobic fermentative transformation. Appl Env Microbiol 200-202. doi:http://aem. asm.org/content $/ 52 / 1 / 200$.abstract

Vogt C, Kleinsteuber S, Richnow H-H (2011) Anaerobic benzene degradation by bacteria. Microbial Biotechnol 710-724. doi:10.1111/j.1751-7915.2011.00260.x

Wilczyńska-Piliszek AJ, Piliszek S, Falandysz J (2012) QSPR models for prediction of the soil sorption coefficient (log KOC) values of 209 polychlorinated trans-azobenzenes (PCt-ABs). J Environ Sci Health A 441-449. doi:10.1080/10934529.2012.646138

Xie N-Z, Liang H, Huang R-B, Xu P (2014) Biotechnological production of muconic acid: current status and future prospects. Biotechnol Adv 615-622. doi:10.1016/j.biotechadv.2014.04.001

Zhan J (2009) Biosynthesis of bacterial aromatic polyketides. Curr Topics Med Chem 1598-1610. doi:http://www.ingentaconnect.com/content/ben/ctmc/2009/00000009/00000017/art00002

Zhang X, Young LY (1997) Carboxylation as an initial reaction in the anaerobic metabolism of naphthalene and phenanthrene by sulfidogenic consortia. Appl Env Microbiol 4759-4764. doi:http://aem.asm.org/content/63/12/4759.abstract

Zhang S, Sun W, Xu L, Zheng X, Chu X, Tian J, Wu N, Fan Y (2012a) Identification of the paranitrophenol catabolic pathway, and characterization of three enzymes involved in the hydroquinone pathway, in Pseudomonas sp. 1-7. BMC Microbiol 27. doi:http://www.biomedcentral. com/1471-2180/12/27

Zhang S, Wang Q, Xie S (2012b) Stable isotope probing identifies anthracene degraders under methanogenic conditions. Biodegradation 221-230. doi:10.1007/s10532-011-9501-1 